\title{
Workplace Resilience and Performance: Workload and Organizational Constraints
}

\author{
Larry A. Mallak \\ Western Michigan University \\ Christopher Shank \\ Western Michigan University
}

Resilience is a key construct in the performance of targeted behaviors for solving problems and taking action in the face of adversity. Yet, not much is known about the outcomes of resilience in the workplace. A structural equation model was conducted to explore the relationships between four factors of workplace resilience as measured by the Workplace Resilience Instrument and barriers to performance as measured by the Organizational Constraints Scale and the Qualitative Workload Inventory. Results suggest higher levels of workplace resilience are correlated with the ability to handle greater workloads and organizational constraints. In particular, sense-making emerged as critical to workplace resilience.

Keywords: resilience, performance, workload, constraints, bricolage, sense-making

\section{INTRODUCTION}

Resilience is a key construct in the performance of targeted behaviors for solving problems and taking action in the face of adversity. The increasing need for quicker decision making in complex systems having severe consequences requires individuals and organizations to have the capacity to make high quality decisions and take effective actions. The recent increase in the frequency of costly natural disasters, responses to the COVID-19 pandemic, and continued vigilant action to thwart terrorist actions represent high-profile situations benefiting from resilient behavior.

Resilience is essential in the execution of workplace behaviors. Since the 1990s, research has increased as attention has progressed from technical performance of tasks to the psychological parameters in which work is done. Resilience has evolved through three phases of construct development (Mallak \& Yildiz, 2016): Foundational (1955-1987), Conceptualization (1988-1999), and Measurement (2000-present).

Foundational work established the theoretical basis for the study of resilience. Werner and Smith's (1979) study of children in Kauai and Kobasa's (1979) work on "hardiness" were among the early studies setting the stage for resilience as a construct in organizations. Conceptual work translated the foundational work into more actionable models, but stopped short of producing instruments to measure resilience. These conceptual works ranged from Weick's (1993) analysis of the Mann Gulch disaster and the invention of the backfire to books on the topic that address the resilience concepts (Conner, 2006; Deevy, 1995).

Initial work in the Measurement phase focused on clinical applications of resilience measurements for individuals experiencing post-traumatic stress disorder (PTSD), severe stress, mental health, and other 
conditions (Connor \& Davidson, 2003; Friborg et al., 2003; Oshio et al., 2003; Sinclair \& Wallston, 2004; Sood et al., 2011; Winwood et al., 2013). These instruments were mostly focused on clinical applications for patients seeking treatment and for their clinicians to design more effective treatments. However, managers and professionals in the workplace were also observing (and probably experiencing) demands on their employees that did not produce clinical indications, yet did require some type of diagnosis and intervention from a managerial perspective. These initial instruments were helpful to clinicians, but not necessarily to practicing managers in the modern workplace. Managers in the modern workplace are typically interested in tools that not only help the employee, but have a value-added element for the organization. This study's focus on the relationships between workplace resilience and proxies for performance seeks to fill that need.

Workplace attention to resilience primarily surfaced in books (Conner, 2006; Deevy, 1995) and consulting firms, with academic treatment lagging. In 1997, Mallak published a set of resilience scales based on research in the U.S. healthcare sector. In 2003, Connor and Davidson published their CD-RISC, an instrument designed for use in more general workplace settings. Research and literature in workplace resilience were now catching up with the clinical research stream established several years prior (Haase, 2004; Hunter \& Chandler, 1999). Mallak and Yildiz published a revised set of workplace resilience scales called the Workplace Resilience Instrument (WRI) in 2016. These scales built on the 1997 work (Mallak, 1997) and updated the instrument to be applicable to multiple industries, not just healthcare. Items in the WRI were rewritten to remove reverse-coding and to focus on the individual. Reverse-coded items were removed to improve the scale's quality (Roszkowski \& Soven, 2010).

\section{THEORY AND RESEARCH QUESTIONS}

\section{Workplace Resilience and Performance}

Research from several key disciplines has led to the current theoretical foundation for the study of workplace resilience. This research focused on the processes deployed in response (or even in advance) of situations requiring resilience. In physical systems, resilience refers to a material's ability to store and return elastic energy (Ashby \& Greer, 2006). Similarly, in the workplace, we seek the ability for an employee to absorb energy from a stressful situation and to return to their original (or improved) condition once the stressor is removed.

Unlike an inanimate material, a person must perform one or more processes to return to their original state. These processes typically take the form of protective factors (Werner, 2000). Protective factors exist in contrast with risk factors (Cohen et al., 1983) which are associated with vulnerability. In Werner's classic study (1993), the risk factors facing children born in Kauai (Hawaii) included absent or alcoholic parents, abuse, and teen motherhood, among others. In the workplace, protective factors emanate from the theories of coping (Carver et al., 1989) and how job stress is handled (Kawada \& Otsuka, 2011).

Coping and responses to job stress seek to move the person's psychological state to an improved state compared with before the adverse situation was encountered. This is reminiscent of the quote often attributed to Friedrich Nietzsche, "That which does not kill me makes me stronger." Similarly, the construct of stress has origins in engineering - stress is defined as the force per unit area but can be conceived as "internal forces that neighboring particles of a continuous material exert on each other" (GoEngineer, n.d.).

Translating this engineering definition to the individual, stress is indeed an internal phenomenon and, like engineering materials, it is manifested physically. Stress is often contrasted with anxiety; anxiety is a cognitive phenomenon of uncertain origin while stress involves physical symptoms having a known origin (adapted from definitions in Stress and Your Health (n.d.) and The Difference Between Stress and Anxiety (2014)).

The relationships between risk factors and protective factors with the construct of resilience are illustrated by several models from the literature. The Youth Resilience Model (Rew \& Horner, 2003) portrays the interaction between risk factors (vulnerability) and protective factors (protection), while treating family and community as part of the sociocultural context for resilience. The Adolescent Resilience Model (Haase, 2004) contains individual and family components for risk and protective factors that seek 
the outcomes of increased resilience and quality of life. Hunter and Chandler's (1999) continuum of resilience in adolescents has adaptive behaviors and self-efficacy at one extreme and risk factors at its other extreme. The resilience scales developed by Wagnild and Young (1993) were based on Block and Block's (1980) ego-resilience (a high level of resilience) and ego-brittleness (vulnerability) and on Rutter's (1985) "buffering effect."

In clinical settings, resilience is measured primarily to provide data to help improve a patient's condition and the clinician's ability to treat that condition. In workplace settings, we may measure resilience for many different reasons, but ultimately, we want to improve performance on the individual, work unit, and organizational levels. Measuring performance is fraught with problems of metric definition and the ability to compare these metrics across organizations, industries, and geographic locations. Additionally, obtaining a supervisor's assessment of a worker's resilience is very difficult and expensive to accomplish when trying to match up the worker and supervisor ratings. If one or the other does not respond, then the entire case generally needs to be omitted from the analysis.

Therefore, this research uses two proxies for performance in an initial step to investigate the role of resilience in the workplace. These two proxies - Quantitative Workload Index (QWI) (Spector \& Jex, 1998) and Organizational Constraints Scale (OCS) (Spector \& Jex, 1998)—provide insights into how a person perceives their workload and how they perceive constraints affecting their ability to perform a task. The QWI is a "measure of perceived amount of work in terms of pace and volume" (Spector \& Jex, 1998) and obtains a worker's perception of how frequently they have more work than they feel can be done or done well. The OCS measures 11 items representing "situations or things that prevent employees from translating ability and effort into high levels of job performance" (Spector \& Jex, 1998, p. 357). The OCS obtains a worker's perception of how frequently they feel it is difficult or impossible to do their job because of a supervisor, equipment, rules, training, interruptions, and other constraints.

The QWI and OCS have been used in many settings to assess the roles of workload and constraints in organizational research. The meta-analysis by Spector and Jex (1998) showed acceptable levels of internal consistency as measured by Coefficient alpha (greater than 0.80). Their analysis of 19 studies provided validation of the QWI and OCS in terms of expected correlations with occupational stress theory and research with the QWI showing high correlations with anxiety and frustration; similarly, the OCS showed high correlations with anxiety and intent to quit (Spector \& Jex, 1998).

As measured by the WRI (Mallak \& Yildiz, 2016), workplace resilience is composed of four factors: Active Problem-Solving (WRI-AP), Team Efficacy (WRI-TE), Confident Sensemaking (WRI-SM), and Bricolage (WRI-BR). A worker with high resilience, as measured by the WRI, is expected to take an active approach to problem-solving, thereby perceiving problems as entities to be solved rather than excuses or reasons why tasks cannot be done. Team Efficacy means the worker has sufficient knowledge and understanding of others' roles and is not easily "thrown off" when a team member is absent or otherwise unavailable. Confident Sensemaking means the worker can make order out of chaos and is not easily dismayed by uncertainty in tasks or the workplace. And, Bricolage means the worker formulates solutions with the materials or information that he or she has on-hand. Therefore, workers with high WRI scores should have the skills and mindset to meet the perception of high workload and the lack of information, equipment, or other constraints. A bricoleur (WRI-BR) does not view the lack of a critical item as a reason why a task cannot be accomplished. A worker who practices Active Problem-Solving has the ability to prioritize tasks so workload does not seem as problematic - the important tasks get done and others do not and this is not a problem to the resilient worker.

\section{Workplace Resilience and Workload}

Although we often view workload as a variable where a greater workload is viewed as a negative organizational condition, research by Pindek, Krajcevska, and Spector (2018) studied work underload. In their study, they present workload as an inverted U variable and studied work underload as a potential stressor in the context of "cyberloafing." Workload was studied for its role as an antecedent of heavy work investment (Tziner et al., 2019). They found that workload's effect on burnout could be partially mediated by work intensity (Tziner et al., 2019). 
Workload is a known stressor (Lanz \& Bruk-Lee, 2017) and therefore individuals with higher levels of resilience should be able to cope better with higher workload than those with lower levels of resilience. In their review of the workload literature, Bowling and Kirkendall (2012) offered a workload definition comprised of both the amount and difficulty of work. Workload has been found to be correlated negatively with social support and positively with negative affectivity, role conflict, role ambiguity, and work-family balance (Bowling et al., 2015). When workload was studied for its relationships with outcomes, workload was found negatively related with psychological and physical well-being; additionally, higher workload was found related to higher absenteeism and intent to leave, but was not found to be related to in-role performance (Bowling et al., 2015). With these relationships as a foundation, we would expect a higher level of workplace resilience to operate as a protective factor against higher workload. This led to our first research question:

\section{RQ1: What is the relationship between WRI factors and QWI?}

\section{Workplace Resilience and Organizational Constraints}

We used workload and constraints as dependent variables in our study of workplace resilience. Resilience operates in contrast with vulnerability. A resilient individual deploys more protective factors and therefore experiences lower vulnerability compared with a low-resilient individual. The ability to get work done is a more generalized measure of performance that can be used across work units, companies, industries, and geographic locations. Perception of workload and constraints work against the ability to get work done, so one's ability to be able to suppress these workload and constraint perceptions should lead to more work getting done at higher levels of quality.

OCS and QWI were used in a study of toxic leadership and job-related affected well-being by Hadadian and Sayadpour (2018). They found that organizational constraints and workload had a significant and negative correlation with job-related well-being; they explain that toxic leaders have a direct effect on workload based on "the corruption of toxic leaders" (Hadadian \& Sayadpour, 2018, p. 143) and that these toxic leaders "pose obstacles to workers in performing their duties" (Hadadian \& Sayadpour, 2018, p. 143). This led to our second research question:

\section{RQ2: What is the relationship between WRI factors and OCS?}

\section{METHODOLOGY}

\section{Sample and Procedure}

An instrument package was distributed electronically to professionals working in full-time positions across multiple industries. Respondent location was targeted to the United States. Because the survey link was sent through several channels-LinkedIn, email, and third-party recruiters - the total number of participants receiving or viewing the link is not known but estimated at 1,000. We received 392 complete responses, of which 357 were usable in our analyses.

\section{Instrumentation and Analysis}

The instrument package contained the Workplace Resilience Instrument (WRI) (Mallak \& Yildiz, 2016), the Quantitative Workload Index (QWI) (Spector \& Jex, 1998) and the Organizational Constraints Scale (OCS) (Spector \& Jex, 1998). Demographics were obtained regarding age, state or country of residence, years of full-time work experience, and gender. Informed consent was obtained from participants per our approved IRB protocol. Response scales for the WRI used an "extent-of-truth" format (e.g., "not true at all" to "true all the time"). QWI and OCS used scales reflecting frequency of occurrence with lower values denoting lower frequencies and higher values denoting higher frequencies of occurrence. This decreased the more subjective nature of extent-of-agreement that is inherent in many scales assessing workplace constructs. 
Of 392 submitted responses, 35 failed to complete at least one screen of the instrument package and were discarded from the analysis; 357 contained either no missing data or randomly distributed missingness and were retained for analysis. Of the retained responses, 338 were complete and 19 had between 1 and 3 missing items. Because of the small proportion of missingness and the ordinal nature of response values, a hot deck approach (Andridge \& Little, 2010) was used to impute valid responses for the 19 cases with missing observations.

After imputation, individual measurement models were specified for the three instruments in the study and confirmatory factor analyses were performed independently on each instrument. Given the presence of ordinal indicators, the feasibility of weighted least squares estimation was investigated and rejected because of an insufficient sample. Instead, a maximum likelihood approach was used to conduct CFA on an input matrix of polychoric correlations between ordinal indicators and assessed the sample data's fit to the theoretical model. In cases where indices of local model fit indicated that the data diverged significantly from the theoretical model, the measurement models were revised by allowing item-unique variances to correlate. In order to avoid damaging instrument interpretability, model revisions were kept to a minimum while still achieving sufficient improvement to model-data fit.

Following revisions to the measurement models of individual instruments, a baseline structural model was specified with paths estimated between all structural components. Maximum likelihood estimation was used to conduct a structural equation model of the relationships between the latent traits underlying instrument responses. Nonsignificant pathways between structural components were trimmed and the structural model was respecified until a parsimonious and interpretable model was identified. Each model iteration was tested for a significant decrement in model-data fit using chi-square difference tests. Data management, cleaning, and analysis were conducted using SAS 9.4; imputation was conducted using the SURVEYIMPUTE procedure, while factor analysis and structural regressions were conducted using the CALIS procedure.

\section{RESULTS}

Demographics are presented for both the organically collected (through LinkedIn and email invitations) and third-party responses in Table 1. CFAs were conducted on initial measurement models for the WRI, OCS, and QWI based on the theoretical factor structures of the three instruments. Model information, internal consistency estimates, and fit statistics for CFAs of the theoretical factor structures are presented in Table 2. Cronbach's Alpha statistics indicated adequate internal consistency (alpha between 0.8 and 0.9) for the WRI, OCS, and QWI, although low item counts for the WRI subscales resulted in lower internal consistency estimates for WRI-AP, WRI-TE, WRI-SR, and WRI-BM. Model-data fit was moderate for the WRI and OCS and approached good fit for the QWI.

\section{TABLE 1}

\section{SAMPLE DEMOGRAPHICS FOR ORGANIC AND THIRD-PARTY DATA SOURCES}

\begin{tabular}{lrrrr}
\hline & \multicolumn{2}{c}{ Organic } & \multicolumn{2}{c}{ Third-Party } \\
\cline { 2 - 5 } Age & $\mathrm{N}$ & Pct & $\mathrm{N}$ & \multicolumn{1}{c}{ Pct } \\
\hline $18-21$ & 9 & $7.56 \%$ & 7 & $2.94 \%$ \\
$25-34$ & 27 & $22.69 \%$ & 43 & $18.07 \%$ \\
$35-44$ & 29 & $24.37 \%$ & 93 & $39.08 \%$ \\
$45-54$ & 29 & $24.37 \%$ & 31 & $13.03 \%$ \\
$55-64$ & 15 & $12.61 \%$ & 36 & $15.13 \%$ \\
$65-74$ & 8 & $6.72 \%$ & 23 & $9.66 \%$ \\
$75+$ & 2 & $1.68 \%$ & 4 & $1.68 \%$ \\
Prefer not to answer & 0 & $0.00 \%$ & 1 & $0.42 \%$ \\
\hline
\end{tabular}




\begin{tabular}{lcccr} 
Region & $\mathrm{N}$ & Pct & $\mathrm{N}$ & Pct \\
\hline South & 49 & $41.18 \%$ & 75 & $31.51 \%$ \\
West & 13 & $10.92 \%$ & 53 & $22.27 \%$ \\
Northeast & 10 & $8.40 \%$ & 56 & $23.53 \%$ \\
Midwest & 47 & $39.50 \%$ & 54 & $22.69 \%$ \\
& & & & \\
Gender & $\mathrm{N}$ & Pct & $\mathrm{N}$ & Pct \\
\hline Female & 22 & $18.49 \%$ & 121 & $50.84 \%$ \\
Male & 97 & $81.51 \%$ & 117 & $49.16 \%$ \\
& & & & \\
Work Experience & $\mathrm{N}$ & Pct & $\mathrm{N}$ & Pct \\
\hline Less than 5 years & 18 & $15.13 \%$ & 10 & $4.20 \%$ \\
5-14 years & 20 & $16.81 \%$ & 49 & $20.59 \%$ \\
15-24 years & 33 & $27.73 \%$ & 83 & $34.87 \%$ \\
25-34 years & 22 & $18.49 \%$ & 33 & $13.87 \%$ \\
35-44 years & 17 & $14.29 \%$ & 42 & $17.65 \%$ \\
45 or more years & 9 & $7.56 \%$ & 21 & $8.82 \%$ \\
\hline
\end{tabular}

TABLE 2

SCALE RELIABILITY AND MODEL FIT OF WRI, OCS, AND QWI

\begin{tabular}{lrrrrrrr}
\hline & \multicolumn{3}{c}{ WRI Subscale Reliability } & \multicolumn{3}{c}{ Instrument Fit Statistics } \\
\cline { 2 - 8 } & AP & TE & SM & BR & WRI & OCS & QWI \\
\hline Model Information & & & & & & & \\
Number of Observations & 357 & 357 & 357 & 357 & 357 & 357 & 357 \\
Number of Variables & 3 & 4 & 7 & 6 & 20 & 11 & 5 \\
Scale Reliability & & & & & & & \\
Cronbach's Alpha & & & & & & \\
& 0.722 & 0.724 & 0.644 & 0.797 & 0.868 & 0.880 & 0.870 \\
Model Fit & & & & & & & \\
Chi-Square & & & & & & & \\
Chi-Square DF & & & & & 714.417 & 453.836 & 92.811 \\
Pr $>$ Chi-Square & & & & & 164 & 44 & 5 \\
Standardized Root Mean Residual & & & & & $<.0001$ & $<.0001$ & $<.0001$ \\
Goodness of Fit Index & & & & & 0.077 & 0.0733 & 0.0506 \\
Comparative Fit Index & & & & & 0.833 & 0.824 & 0.904 \\
Akaike Information Criterion & & & & & 0.807 & 0.808 & 0.920 \\
RMSEA Estimate & & & & & 0.097 & 497.836 & 112.811 \\
Lower 90\% Confidence Limit & & & & & 0.090 & 0.162 & 0.222 \\
Upper 90\% Confidence Limit & & & & & 0.104 & 0.175 & 0.184 \\
\hline
\end{tabular}

A baseline SEM model was specified with unconstrained paths between the latent factors for the OCS, QWI, and the four WRI subscales. Given our informed understanding about the directionality of relationships between these constructs, this model used all four WRI subscales as predictor variables for both OCS and QWI, and OCS was included as a predictor of QWI. Factor covariances between the four WRI subscales were also estimated. To improve the fit of the model to the sample data while maintaining the theoretical integrity and interpretability of the instruments, three model revisions were implemented, allowing error covariances between item OCS-1 and OCS-5, between OCS-7 and OCS-9, and between QWI-1 and QWI-2. This baseline model demonstrated adequate model-data fit. However, Wald tests 
indicated that several of the paths between latent variables did not contribute significant explanatory power to the model and reduced model parsimony. A stepwise model trimming procedure was used to remove nonsignificant paths until any further changes would have resulted in significant reductions to model-data fit.

Four model revisions were implemented to the baseline model. After removing a nonsignificant structural path, the model was specified to check for significant decrement in model fit using chi-square difference tests. Removing the path between WRI-TE and QWI resulted in a chi-square difference of 0.019 with $1 \mathrm{DF}, \mathrm{p}=0.890$; the path between WRI-BR and QWI yielded a chi-square difference of 0.511 with 1 $\mathrm{DF}, \mathrm{p}=0.475$; the path between WRI-TE and OCS resulted in a chi-square difference of 1.690 with $1 \mathrm{DF}$, $\mathrm{p}=0.194$; and the path between WRI-AP and QWI gave a chi-square difference of 2.223 with $1 \mathrm{DF}, \mathrm{p}=0.136$. Any further model revisions would have significantly decreased model fit. Fit statistics for the baseline and revised structural equation models are presented in Table 3.

\section{TABLE 3 \\ MODEL FIT STATISTICS FOR STRUCTURAL EQUATION MODELS}

\begin{tabular}{lrr}
\hline & Baseline Model & Final Model \\
\hline Model Information & & \\
Number of Observations & 357 & 357 \\
Number of Variables & 36 & 36 \\
& & \\
Model Fit & & 2051.660 \\
Chi-Square & 576 & 580 \\
Chi-Square DF & $<.0001$ & $<.0001$ \\
Pr $>$ Chi-Square & 0.080 & 0.081 \\
Standardized Root Mean Residual & 0.772 & 0.772 \\
Goodness of Fit Index & 0.786 & 0.786 \\
Comparative Fit Index & 2227.216 & 2223.660 \\
Akaike Information Criterion & 0.085 & 0.084 \\
RMSEA Estimate & 0.081 & 0.081 \\
Lower 90\% Confidence Limit & 0.089 & 0.088 \\
Upper 90\% Confidence Limit & & \\
Chi-Square Difference Test & & 4.444 \\
Chi-Square Difference & & 4 \\
Difference DF & & 0.349 \\
Pr $>$ Chi-Square Diff & & \\
\hline
\end{tabular}

A path diagram for the revised model with standardized regression weights is presented in Figure 1. All four WRI subscales covaried with one another. However, they were not all equally strong predictors of OCS or QWI. Contrary to our expectations, WRI-TE was not related to either OCS or QWI. WRI-AP and WRI-BR were negatively related to OCS, while WRI-SM was both a strong positive predictor of OCS and a moderately positive predictor of QWI. OCS was negatively related to QWI. Because of the reverse coding of the OCS, the path diagram can be interpreted to suggest that: a) higher levels of confident sense-making are predictive of lower levels of organizational constraints and slightly higher workloads; b) higher levels of active problem-solving and bricolage are predictive of somewhat higher levels of organizational constraints, and c) higher organizational constraints are strongly predictive of higher workloads. 
FIGURE 1

STANDARDIZED PATH DIAGRAM OF FINAL STRUCTURAL EQUATION MODEL

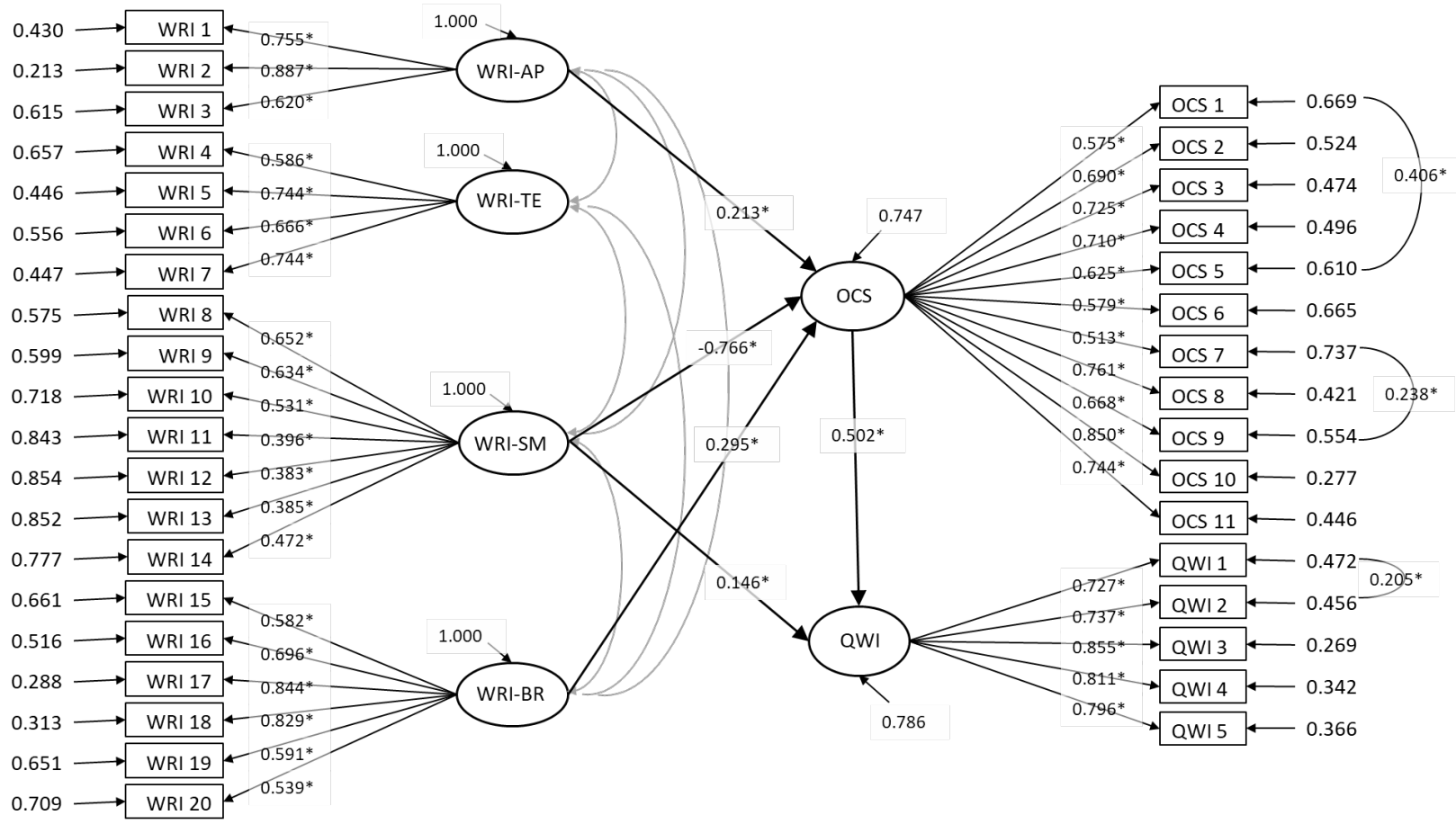

\section{DISCUSSION AND IMPLICATIONS}

Finding statistically significant relationships between workplace resilience and performance was the primary objective of this study. We used organizational constraints and workload as proxies for performance so we could gain an initial view into the resilience-performance relationship. Using the OCS and the QWI allowed us to build a testable research model and methodology to begin studying these important performance linkages. The major findings from this study follow along with interpretation of those findings for the study's research questions.

\section{Higher Sense-Making Predicts Higher Workload}

People in situations with higher workloads are more likely to deploy sensemaking to deal with workload and do their jobs more effectively. Higher workload implies the potential for more chaotic situations. Workers who can approach situations with confidence and can perform the roles of their colleagues (SM) tend to have higher ability to handle increased workload demands corresponding with higher scores on QWI.

\section{Higher Constraints Predicts Higher Workload}

The more perceived barriers a person faces in getting the work done, the longer that work is perceived to take. In fact, the more constraints faced by a worker, the more likely they are to report frequent occurrences of having to work fast, work hard, or have more work than time to get it done or done well. The more one reports that things are in their way (i.e., constraints), the more likely they report it's difficult to get their job done, constituting a higher workload.

This research found support for RQ1 - the relationship between resilience and workload — by providing evidence of significant relationships between WRI factors and QWI. 


\section{Higher Active Problem Solving Predicts Higher Constraints}

This finding suggests that active problem-solvers are more likely to deploy a problem-solving framework that includes constraints. Avoidance of constraints is not typically a path to a successful outcome. Acknowledgment of constraints and including them in the problem-solving process is the basis for most science, engineering, and social science problem-solving processes. Continuing the habit of seeking, acknowledging, and including constraints in our workplace situations should lead to better outcomes and make us more likely to be aware of how those constraints affect our work. Employees in circumstances with more perceived constraints are more likely to develop problem-solving resilience strategies.

\section{Higher Sense-Making Strongly Predicts Lower Constraints}

It is possible that sense-makers are drawn to circumstances with fewer perceived constraints or are less likely to interpret constraints as negatively impacting their work. Reversing the relationship, i.e., stating that lower OCS predicts higher sense-making or that people who perceive many constraints don't use sensemaking, doesn't fit with the use of sense-making and our understanding of the role of constraints in these situations. However, looking at the reverse relationships with respect to AP and BR does appear to aid interpretation: people with high perception of constraints are more likely to turn to AP and BR resilience skills over sense-making. Reviewing the scale items for SM and OCS, it appears that SM is definitionally an absence of constraints - individuals with high SM have already identified constraints and reduced the effects of those constraints.

\section{Higher Bricolage Predicts Higher Constraints}

A skillset oriented towards handling unexpected and chaotic circumstances becomes more valuable when constraints are perceived to have a greater impact on work. Again, causality is unclear-people with high bricolage could be drawn to situations with more constraints, or people in situations with more constraints may be forced to develop bricolage skills. Workers with higher levels of bricolage report higher constraints, suggesting the ability to work more effectively under higher levels of constraints.

This research found support for RQ2 - the relationship between resilience and constraints - by providing evidence of significant relationships between WRI factors and OCS.

\section{The Sense-Making Triangle}

In Figure 2, we observed a set of relationships we call "the Sense-Making Triangle." The subset of relationships anchored on sense-making illustrates the apparent central role of SM as a factor addressing how constraints and workload interact with the resilience of an employee. This reflects two different aspects of the relationships to organizational work barriers and total workload. First, more constraints create more work. When a person faces more constraints, they typically must deploy more innovative thought patterns and behavioral options. Sense-making, whether individually or collectively performed, seeks to construct a shared meaning of the experience being confronted. Second, the resilience skillset (sense-making) associated with minimizing constraints is heightened in conditions with greater workloads. Sense-making reduces constraints and is associated with higher workloads. Workers who perceive higher workloads may employ this resilience factor to minimize barriers to their work. SM forms an anchor between workload and constraints. 


\section{FIGURE 2 \\ THE SENSE-MAKING TRIANGLE}

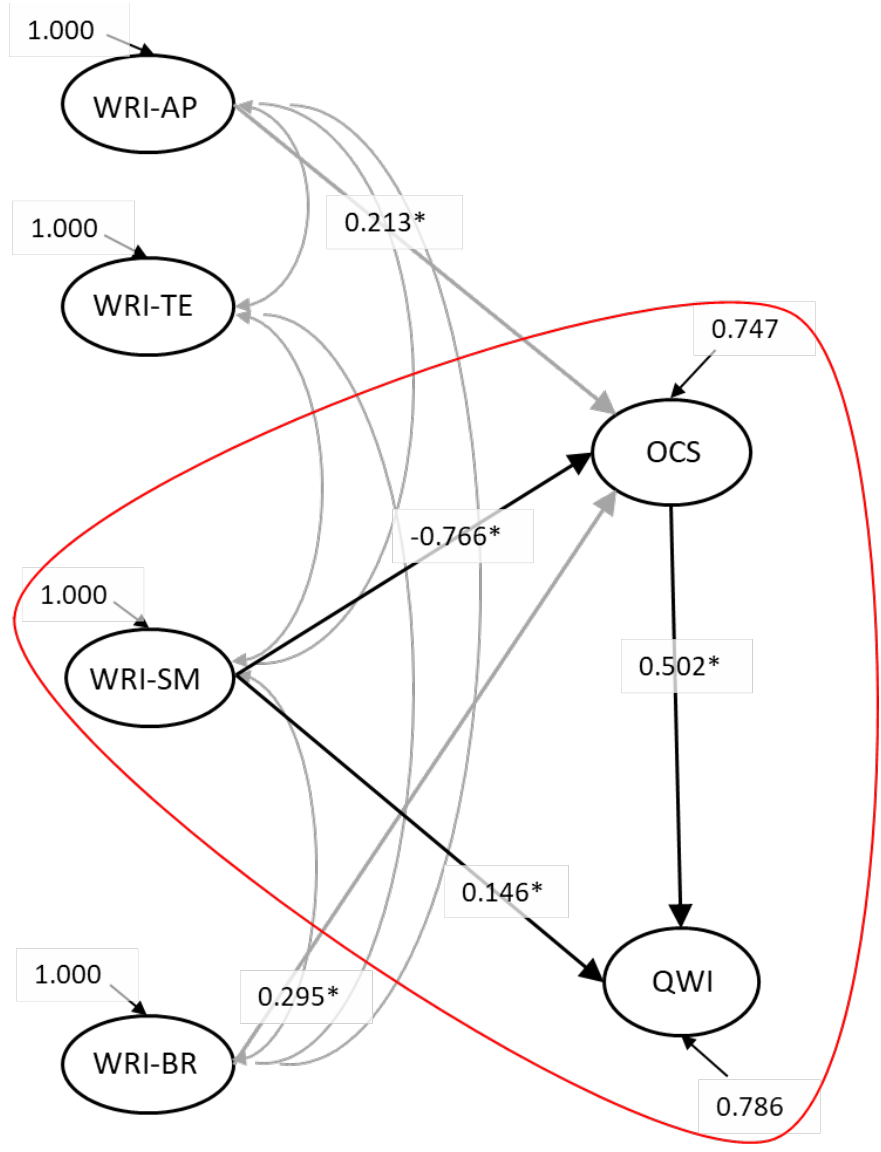

A worker with greater SM abilities is better equipped to handle constraints and can deal with more extreme workload environments effectively. If a person is better able to handle a tougher workload, constraints are kept in check. Sense-making behaves as a more proactive approach to deal with constraints or a method to situate oneself in a way that avoids constraints before they occur-bricolage and active problem-solving are reactive approaches to overcome barriers once they've occurred. Higher bricolage employees can react effectively when faced with constraints. SM has an innate ability to proactively deal with constraints.

\section{Interpretation of Nonsignificant Associations}

TE had no significant correlation with either OCS or QWI. Although we would expect any validated resilience factor to be associated with the performance variables, there was no evidence for TE's relationship with resilience factors in the current study. One possible explanation is that TE is a team-based measure being used in an individual measurement setting. Future work may investigate administering the WRI to work teams so there is a clearly identifiable referent for the team efficacy items.

AP and BR were significantly correlated with OCS, but had no significant correlations with QWI. One possible interpretation is that individuals who practice active problem solving and/or bricolage are unaffected based on workload levels - whether high or low. Their problem-solving approaches and use of bricolage may help them perform well despite workload levels, but increased constraints (OCS) draw upon increased reliance on these resilience factors. 


\section{CONCLUSIONS, LIMITATIONS, AND DIRECTIONS FOR FUTURE RESEARCH}

This study provided promising findings concerning the relationships between resilience and performance. In particular, it suggested links between resilience and two perceived barriers to performance: workload (RQ1) and organizational constraints (RQ2). These indicators of performance were negative, reflecting the degree to which performance may be impeded and therefore demanding increased use of certain resilience factors in order to overcome them. However, these measures do not capture the performance actually achieved as a result of implementing strategies for resilience. Future confirmatory research on the resilience-performance relationship should incorporate a direct positive measure of in-role performance such as work output to investigate whether perceived workload and organizational constraints mediate the relationship between resilience and performance.

This research was primarily exploratory in nature and therefore relied on a sample recruited on the basis of convenience. The sample was further split between organically collected and third-party responses. Although the demographic features of these two groups diverged, neither group was sufficiently large to conduct an analysis of differences in response patterns and measurement invariance between the groups. Measurement differences between these groups could explain marginal values for model-data fit across various indices; unfortunately, without a more large-scale confirmatory study the sources of sample-specific misfit are purely speculative. However, the study did produce findings and conclusions relevant to the stated research questions.

We set out to investigate relationships between workplace resilience and performance. Using established instruments, we discovered several statistically significant relationships having implications for the workplace. This study used constraints and workload measures as proxies for performance. We discovered initial relationships using these measures so future research can investigate in greater depth to learn more about these relationships and to surface more detailed information regarding the roles of active problem-solving, sense-making, team efficacy, and bricolage as workplace resilience factors. Future research should investigate how the four WRI factors influence the execution of work tasks when faced with workplace constraints and varying perceptions of workload. We seek to discover the skill sets and protective factors to aid the modern worker to build effectiveness and resilience in the face of these undercurrents. This work is an initial step toward that goal.

\section{REFERENCES}

Andridge, R.R., \& Little, R.J.A. (2010). A Review of Hot Deck Imputation for Survey Non-response. International Statistical Review, 78(1), 40-64. https://doi.org/10.1111/j.1751-5823.2010.00103.x

Ashby, M.F., \& Greer, A.L. (2006). Metallic glasses as structural materials. Viewpoint Set No: 37. On Mechanical Behavior of Metallic Glasses, 54(3), 321-326. https://doi.org/10.1016/j.scriptamat.2005.09.051

Block, J.H., \& Block, J. (1980). Role of ego-control and ego-resiliency in the organization of behavior. In Development of cognition, affect, and social relations / edited by W. Andrew Collins. Hillsdale, N.J.: L. Erlbaum Associates. Retrieved from https://agris.fao.org/agrissearch/search.do?recordID $=$ US201302065890

Bowling, N.A., \& Kirkendall, C. (2012). Workload: A Review of Causes, Consequences, and Potential Interventions. In J. Houdmont, S. Leka, \& R.R. Sinclair (Eds.), Contemporary Occupational Health Psychology (pp. 221-238). John Wiley \& Sons, Ltd. https://doi.org/10.1002/9781119942849.ch13

Bowling, N.A., Alarcon, G.M., Bragg, C.B., \& Hartman, M.J. (2015). A meta-analytic examination of the potential correlates and consequences of workload. Work \& Stress, 29(2), 95-113. https://doi.org/10.1080/02678373.2015.1033037

Carver, C.S., Scheier, M.F., \& Weintraub, J.K. (1989). Assessing coping strategies: A theoretically based approach. Journal of Personality and Social Psychology, 56(2), 267-283. https://doi.org/10.1037/0022-3514.56.2.267 
Cohen, S., Kamarck, T., \& Mermelstein, R. (1983). A global measure of perceived stress. Journal of Health and Social Behavior, 24(4), 385-396.

Conner, D. (2006). Managing at the Speed of Change: How Resilient Managers Succeed and Prosper Where Others Fail. Random House.

Connor, K.M., \& Davidson, J.R.T. (2003). Development of a new resilience scale: The Connor-Davidson Resilience Scale (CD-RISC). Depression and Anxiety, 18(2), 76-82. https://doi.org/10.1002/da.10113

Deevy, E. (1995). Creating the Resilient Organization: A Rapid Response Management Program. Prentice Hall.

Friborg, O., Hjemdal, O., Rosenvinge, J.H., \& Martinussen, M. (2003). A new rating scale for adult resilience: What are the central protective resources behind healthy adjustment? International Journal of Methods in Psychiatric Research, 12(2), 65-76. https://doi.org/10.1002/mpr.143

GoEngineer. (n.d.). Stress-GoEngineer. Retrieved November 14, 2014, from $\mathrm{http} / /$ www.goengineer.com/glossary/stress/

Haase, J.E. (2004). The adolescent resilience model as a guide to interventions. Journal of Pediatric Oncology Nursing: Official Journal of the Association of Pediatric Oncology Nurses, 21(5), 289299; discussion 300-304. https://doi.org/10.1177/1043454204267922

Hadadian, Z., \& Sayadpour, Z. (2018). Relationship between Toxic Leadership and Job Related Affective Well-Being: The Mediating Role of Job Stress. European Online Journal of Natural and Social Sciences, 7(1(s)). Retrieved from http://european-science.com/eojnss_proc/article/view/5398

Holmes, L. (2014, February 25). The Difference Between Stress and Anxiety. HuffPost. Retrieved from https://www.huffpost.com/entry/stress-anxiety-difference_n_4833172

Hunter, A.J., \& Chandler, G.E. (1999). Adolescent Resilience. Image: The Journal of Nursing Scholarship, 31(3), 243-247. https://doi.org/10.1111/j.1547-5069.1999.tb00488.x

Kawada, T., \& Otsuka, T. (2011). Relationship between job stress, occupational position and job satisfaction using a brief job stress questionnaire (BJSQ). Work (Reading, Mass.), 40(4), 393 399. https://doi.org/10.3233/WOR-2011-1251

Kobasa, S.C. (1979). Stressful life events, personality, and health: An inquiry into hardiness. Journal of Personality and Social Psychology, 37(1), 1-11. https://doi.org/10.1037//0022-3514.37.1.1

Lanz, J.J., \& Bruk-Lee, V. (2017). Resilience as a moderator of the indirect effects of conflict and workload on job outcomes among nurses. Journal of Advanced Nursing, 73(12), 2973-2986. https://doi.org/10.1111/jan.13383

Mallak, L.A. (1997). Measuring resilience in health care provider organizations. Health Manpower Management, 24(4-5), 148-152. https://doi.org/10.1108/09552069810215755

Mallak, L.A., \& Yildiz, M. (2016). Developing a workplace resilience instrument. Work (Reading, Mass.), 54(2), 241-253.

MedlinePlus. (n.d.). Stress and your health: MedlinePlus Medical Encyclopedia. Retrieved November 12, 2020, from https://medlineplus.gov/ency/article/003211.htm

Oshio, A., Kaneko, H., Nagamine, S., \& Nakaya, M. (2003). Construct validity of the Adolescent Resilience Scale. Psychological Reports, 93(3 Pt 2), 1217-1222. https://doi.org/10.2466/pr0.2003.93.3f.1217

Pindek, S., Krajcevska, A., \& Spector, P.E. (2018). Cyberloafing as a coping mechanism: Dealing with workplace boredom. Computers in Human Behavior, 86, 147-152. https://doi.org/10.1016/j.chb.2018.04.040

Rew, L., \& Horner, S.D. (2003). Youth Resilience Framework for reducing health-risk behaviors in adolescents. Journal of Pediatric Nursing, 18(6), 379-388. https://doi.org/10.1016/s08825963(03)00162-3

Roszkowski, M.J., \& Soven, M. (2010). Shifting gears: Consequences of including two negatively worded items in the middle of a positively worded questionnaire. Assessment \& Evaluation in Higher Education, 35(1), 113-130. https://doi.org/10.1080/02602930802618344 
Rutter, M. (1985). Resilience in the face of adversity. Protective factors and resistance to psychiatric disorder. The British Journal of Psychiatry: The Journal of Mental Science, 147, 598-611. https://doi.org/10.1192/bjp.147.6.598

Sinclair, V.G., \& Wallston, K.A. (2004). The development and psychometric evaluation of the Brief Resilient Coping Scale. Assessment, 11(1), 94-101. https://doi.org/10.1177/1073191103258144

Sood, A., Prasad, K., Schroeder, D., \& Varkey, P. (2011). Stress management and resilience training among Department of Medicine faculty: A pilot randomized clinical trial. Journal of General Internal Medicine, 26(8), 858-861. https://doi.org/10.1007/s11606-011-1640-x

Spector, P.E., \& Jex, S.M. (1998). Development of four self-report measures of job stressors and strain: Interpersonal Conflict at Work Scale, Organizational Constraints Scale, Quantitative Workload Inventory, and Physical Symptoms Inventory. Journal of Occupational Health Psychology, 3(4), 356-367. https://doi.org/10.1037/1076-8998.3.4.356

Tziner, A., Buzea, C., Rabenu, E., Shkoler, O., \& Truta, C. (2019). Understanding the Relationship Between Antecedents of Heavy Work Investment (HWI) and Burnout. The AMFITEATRU ECONOMIC Journal, 21(50), 153-153.

Wagnild, G.M., \& Young, H.M. (1993). Development and psychometric evaluation of the Resilience Scale. Journal of Nursing Measurement, 1(2), 165-178.

Weick, K.E. (1993). The Collapse of Sensemaking in Organizations: The Mann Gulch Disaster. Administrative Science Quarterly, 38(4), 628-652. JSTOR. https://doi.org/10.2307/2393339

Werner, E.E. (1993). Risk, resilience, and recovery: Perspectives from the Kauai Longitudinal Study. Development and Psychopathology, 5(4), 503-515. https://doi.org/10.1017/S095457940000612X

Werner, E.E. (2000). Protective factors and individual resilience. In Handbook of early childhood intervention, 2nd ed (pp. 115-132). Cambridge University Press. https://doi.org/10.1017/CBO9780511529320.008

Werner, E.E., \& Smith, R.S. (1979). A Report from the Kauai Longitudinal Study. Journal of the American Academy of Child Psychiatry, 18(2), 292-306. https://doi.org/10.1016/S00027138(09)61044-X

Winwood, P.C., Colon, R., \& McEwen, K. (2013). A practical measure of workplace resilience: Developing the resilience at work scale. Journal of Occupational and Environmental Medicine, 55(10), 1205-1212. https://doi.org/10.1097/JOM.0b013e3182a2a60a 